\title{
A Mutation in the Dystrophin Gene Selectively Affecting Dystrophin Expression in the Heart
}

\author{
Francesco Muntoni,, Lesley Wilson, ${ }^{*}$ Gianni Marrosu, ${ }^{\ddagger}$ Maria Giovanna Marrosu, ${ }^{\ddagger}$ Carlo Cianchetti, ${ }^{\ddagger}$ Luisa Mestroni," \\ Antonello Ganau, ${ }^{5}$ Victor Dubowitz," and Caroline Sewry* \\ *Department of Paediatrics \& Neonatal Medicine, Hammersmith Hospital, London W12 ONN, UK; ${ }^{\ddagger}$ Child Neurology \& Psychiatry \\ Institute, Cagliari; and 8 Internal Medicine Institute, Sassari; "International Centre for Genetic Engineering and Biotechnology, \\ Trieste, Italy
}

\begin{abstract}
We have previously shown in a large $\mathrm{X}$-linked pedigree that a deletion removing the dystrophin muscle promoter, the first muscle exon and part of intron 1 caused a severe dilated cardiomyopathy with no associated muscle weakness. Dystrophin expression was present in the muscle of affected males and transcription studies indicated that this dystrophin originated from the brain and Purkinje cell isoforms, upregulated in this skeletal muscle. We have now studied dystrophin transcription and expression in the heart of one member of this family. In contrast to the skeletal muscle, dystrophin transcription and expression were absent in the heart, with the exception of the distal Dp71 dystrophin isoform, normally present in the heart. The 43- and 50-kD dystrophin-associated proteins were severely reduced in the heart, despite the presence of Dp71, but not in skeletal muscle. The absence of dystrophin and the down-regulation of the dystrophin-associated proteins in the heart accounted for the severe cardiomyopathy in this family. The mutation present in these males selectively affects dystrophin expression in the heart; this could be secondary to the removal of cardiac-specific regulatory sequences. This family may represent the first example of a mutation specifically affecting the cardiac expression of a gene, present physiologically in both the skeletal and cardiac muscles. (J. Clin. Invest. 1995. 96:693-699.) Key words: Dp71 • skeletal muscle • muscular dystrophy $\bullet$ dystrophin-associated proteins $\bullet$ gene expression
\end{abstract}

\section{Introduction}

Dilated cardiomyopathies are characterized by ventricular dilatation and impaired systolic function. They are the most common form among the various types of primary myocardial disorders characterized by impaired ventricular function. The prevalence of dilated cardiomyopathies has recently been estimated at 36.5/100,000 the United States (1). The majority of them

Address correspondence to Dr. Francesco Muntoni, Department of Paediatrics \& Neonatal Medicine, Royal Postgraduate Medical School, Hammersmith Hospital, Du Cane Road, London W12 ONN, UK. Phone: 181740 3295; FAX: 1817408281.

Received for publication 30 January 1995 and accepted in revised form 21 April 1995.

J. Clin. Invest.

(C) The American Society for Clinical Investigation, Inc.

0021-9738/95/08/0693/07 \$2.00

Volume 96, August 1995, 693-699 have no identifiable cause (idiopathic dilated cardiomyopathy). A proportion of these forms, estimated to be at least $20 \%$ of the total, show a clear Mendelian inheritance (2), and various patterns of inheritance, including autosomal dominant $(3,4)$, autosomal recessive (5), and X-linked forms (6) (X-linked dilated cardiomyopathy, $\mathrm{XLDCM}^{1}$ ), have all been documented. There is apparently no clinical difference between these various familial and sporadic forms, and their identification relies on careful examination of the pedigree and, in addition, the study of first degree relatives. Molecular biological techniques have now enabled dissection of this group of disorders, and linkage to the dystrophin gene has been found in two $X$-linked pedigrees (7), and mutations in this gene described both in XLDCM families (8) and sporadic cases (9).

An autosomal dominant form has also been recently mapped to chromosome 1p1-1q1 (10). The fact that not all autosomal dominant families with dilated cardiomyopathy are linked to chromosome 1 suggests the existence of at least a second locus (10) (Mestroni, unpublished observation). This heterogeneity is not surprising, considering the number of genes that contribute to cardiomyocyte integrity and contractility. In the various reported XLDCM families in which a dystrophinopathy was demonstrated (7-9), no muscle weakness nor clinical evidence of skeletal muscle involvement was found. Although under physiological circumstances dystrophin is expressed at equal levels in the skeletal and cardiac muscles, and one would therefore expect mutations in the dystrophin gene to equally affect both tissues, the families with XLDCM indirectly supported the concept that some mutations might primarily affect dystrophin expression in the heart. In the XLDCM cases in which a deletion of the dystrophin gene was found $(8,9)$, the lack of availability of cardiac tissue made it impossible to compare dystrophin gene expression in the skeletal muscle with that in the heart. This only allowed one to speculate on the possible reasons for this peculiar disease course. In particular, it was unclear if a protein that could maintain its function in the skeletal muscle but not in the heart was produced or if the mutation selectively affected dystrophin expression only in the heart (11).

We have now been able to obtain a cardiac biopsy from one member of the XLDCM family we reported before (8). We report here the comparative analysis of dystrophin transcription and expression in the skeletal muscle and heart of this individual. We found that no dystrophin was produced in his heart, with the exception of the Dp71 distal isoform $(12,13)$. The dystrophin-associated-glycoproteins, or DAGs (14-16), al-

1. Abbreviations used in this paper: BMD, Becker muscular dystrophy cTnC, slow/cardiac troponin C; DAG, Dystrophin-associated-glycoprotein; DMD, Duchenne muscular dystrophy; XLDCM, X-linked dilated cardiomyopathy. 


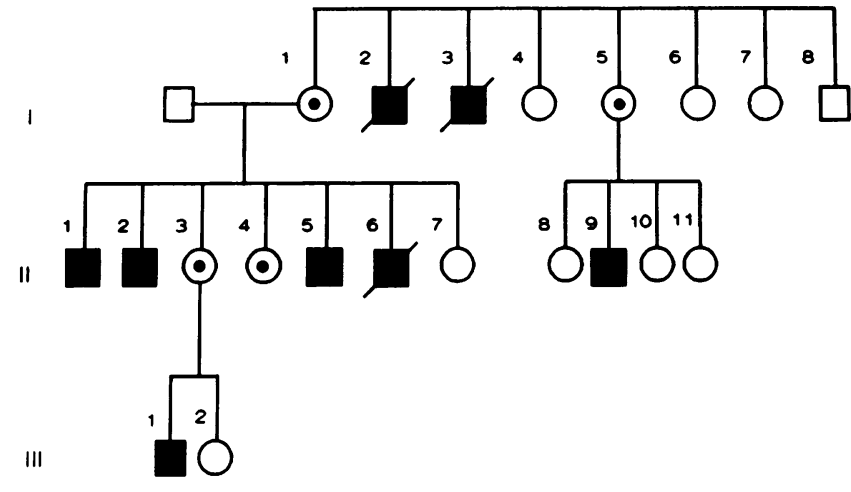

Figure 1. Pedigree of the XLDCM family.

though expressed in the skeletal muscle, were severely reduced in the heart, despite the Dp71 expression. Our results strongly suggest that the mutation found in this family selectively affects dystrophin expression in the heart but not in the skeletal muscle.

\section{Methods}

The XLDCM family (Fig. 1) has previously been described in detail (8). Muscle biopsies and the cardiac biopsy were obtained after informed consent. This study was approved by the ethics committee of the two hospital involved in the clinical evaluation of patients.

Histology and immunocytochemistry. A needle biopsy of skeletal muscle was obtained from individuals II-2, II-6, and III-1. The left ventricular biopsy ( $\sim 1.5 \mathrm{mg}$ of tissue) was obtained from individual II2 during cardiac catheterization performed during a study aimed at assess the patient cardiac function, with the view to a cardiac transplant. The samples were studied according to standard techniques (17), including immunocytochemistry using a biotin-Streptavidin Texas red method. $6-\mu \mathrm{m}$ unfixed cryostat sections were immunostained using a panel of antibodies to dystrophin (Novocastra Laboratories, Newcastle-uponTyne, UK), the 43-kD (gift of L. Nicholson) and 50-kD (gift of K.P Cambell), utrophin (gift of G. E. Morris) and merosin (Chemicon) (1820). Western blot analysis was not performed because of the scarcity of the cardiac tissue obtained with the biopsy.

Reverse transcription and PCR. Total RNA (21) was isolated from frozen skeletal muscle biopsies of the patients who had a needle muscle biopsy as part of the diagnostic procedure. Frozen right ventricular wall cardiac muscle was obtained from individuals that underwent cardiac transplantation for coronary artery disease. The lymphocyte mRNA was obtained from fresh blood of normal individuals. The cDNA synthesis was performed using random hexanucleotide primers, following the procedure already described $(11,22)$. PCR was performed in a reaction volume of $25 \mu \mathrm{l}$ containing the cDNA template $(2 \mu \mathrm{g})$ and oligonucleotide primers designed to amplify the mid-rod domain of dystrophin (23) (exon 30-31 or 30-33, oligonucleotides 30: 5' GAGGCTGTAGGAGGCAAAAGTTG $3^{\prime}$; 31: 5' ATCCAATCTGATTTGAC AAGTCAT 3'; 33: 5' GACGGAAAATCCCAAAGAACTTGA 3', respectively), the L-type isoform (24) (L-promoter-exon 6, for the first PCR round, oligonucleotides $5^{\prime}$ CTAGTTCTCCAAGCTCTACTCATG $3^{\prime}$ and $5^{\prime}$ ACCCAGCTCA GGAGAATCTTTTCA 3', respectively, while a reverse oligonucleotide located in exon $4,5^{\prime}$ ACATTGTTCAGGGCATGAACTCT $3^{\prime}$, was used in the second PCR round). Oligonucleotides for amplifying the $\alpha 2$ laminin chain gene (25) (also referred to as merosin) were a) forward oligonucleotide 5' CTGTGATCAGTGCTGT CCAGGGATT 3', position 1001-1025 and b) reverse oligonucleotide 5' TCGAGCATGTTTCTCATCCTTGAC 3', position 1350-1326), while those for the Dp71 transcript were derived from the published sequences (26): (a) forward primer $5^{\prime}$ TCCACTCGTACCCACACTCGAC 3'; (b) reverse primer (located in exon 63) 5' GCTAAAGAC-
TGGTAGAGCTCTGTC 3 '. PCR reactions $(25 \mu \mathrm{l})$ used $0.5 \mathrm{U}$ Taq polymerase, $0.25 \mathrm{M}$ each primer, $200 \mathrm{~m}$ each dNTP, in $10 \mathrm{mM}$ Tris$\mathrm{HCL}, \mathrm{pH} 8.3,50 \mathrm{mM} \mathrm{KCl}$ and $1.5 \mathrm{mM} \mathrm{MgCl}_{2}$. Amplification conditions were $94^{\circ} \mathrm{C}$ denaturation for $10 \mathrm{~min}$, followed by $94^{\circ} \mathrm{C}(30 \mathrm{~s}), 58^{\circ} \mathrm{C}$ annealing $(60 \mathrm{~s})$, and $72^{\circ} \mathrm{C}$ extension $(120 \mathrm{~s})$, for 26 cycles. $9 \mu \mathrm{l}$ of the reactions were analyzed on $2.5 \%$ agarose gels containing $0.2 \mathrm{grams} / \mathrm{ml}$ of ethidium bromide prior to photography. A second round of PCR was performed when studying the transcription of the L-type promoter.

\section{Results}

\section{Skeletal muscle biopsy}

Histology. On muscle biopsy, a similar picture was found in all three affected individuals: there was some variability in fiber size with the presence of mildly hypertrophic and atrophic fibers, and a moderate increase in internal nuclei (Fig. $2 \mathrm{~A}$ ). There was no increase in interstitial connective tissue.

Immunocytochemistry. (a) Dystrophin and DAGs. Although all fibers were continuously labeled with antibodies to dystrophin and the 43- and 50-kD DAGs, the intensity of fluorescent labeling was paler than in control muscle, as judged by visual inspection (Fig. 2, $C$ and $E$ and Fig. 3, $A$ and $b$ ). (b) Merosin. Labeling for merosin was normal (not shown). (c) Utrophin. Antibodies to utrophin showed labeling of all blood vessels and moderate labeling of the sarcolemma of several fibers (Fig. $3 E$ ).

\section{Cardiac biopsy}

Histological picture. The histological picture of the cardiac biopsy showed a marked variability of fiber size and severe fibrosis (Fig. $2 B$ ).

Immunocytochemistry. (a) Dystrophin and DAGs. No immunoreactivity was observed with antibodies directed towards the $\mathrm{N}$-terminal (Fig. $2 \mathrm{D}$ ) and mid-rod-region of dystrophin (not shown). A weak but clear immunoreactivity was observed at the sarcolemma of each cardiomyocyte using a $\mathrm{COOH}$-terminal anti-dystrophin antibody (Fig. $2 F$ ). This pattern of dystrophin expression suggests that this represent the Dp71 dystrophin isoform. Immunocytochemistry performed with antibodies to the 43- and 50-kD DAG showed a severe reduction of these two proteins, as judged by visual evaluation (Fig. 3, $B$ and $D$ ). (a) Merosin. Merosin immunolabeling was normal (not shown). (c) Utrophin staining showed marked increase in staining at the periphery of almost every cardiomyocyte (Fig. $3 F$ ).

\section{Reverse transcription and PCR}

Co-amplification of the cDNA from normal skeletal and cardiac muscle using the oligomers for the mid-rod region (exons 30 33 ) of dystrophin and for the $\alpha 2$ laminin gene gave the expected size products in both tissues (Fig. 4). Regarding the patient's tissues, amplification of both dystrophin and the $\alpha 2$ laminin chain gene was obtained in the skeletal muscle (Fig. 4); in the heart, however, no amplification of dystrophin could be obtained (Fig. 4).

Regarding the transcription of the novel dystrophin L-isoform (24), no amplification was obtained after a single course of PCR in the various samples analyzed (normal skeletal and cardiac muscle, lymphocytes, Fig. 5). A band of the expected size (also including exon two, and therefore in contrast to what previously reported) (24), was detectable only after a second round of PCR in the lymphocytes but not in the other tissues, including the patient's material (Fig. 5).

The Dp71 mRNA was amplified from normal fetal muscle, 

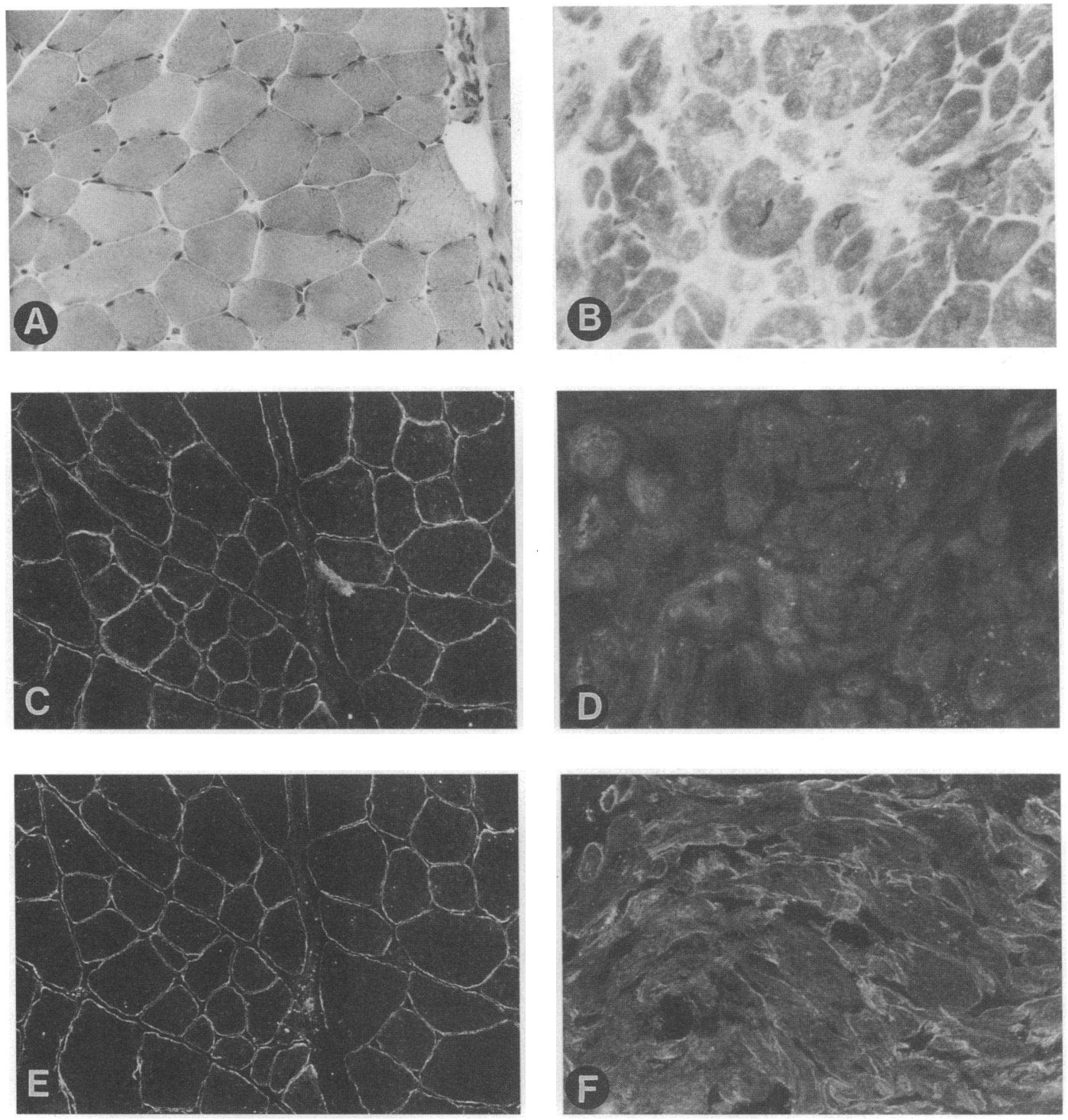

Figure 2. Cryostat sections of skeletal $(A, C$, and $E)$ and cardiac $(B, D$, and $F)$ muscle from a XLDCM family affected member, stained with the Gomori's trichrome $\left(A\right.$ and $B$ ), and immunolabeled with antibodies to the $\mathrm{NH}_{2}$-terminal region of dystrophin $(C$ and $D)$, and to the $\mathrm{COOH}$-terminal region of dystrophin $(E$ and $F)$. Note the marked pathology in the heart compared with skeletal muscle, and the presence of dystrophin in skeletal muscle with both $\mathrm{NH}_{2}$ and $\mathrm{COOH}$-terminal antibodies, in contrast to the absence of $\mathrm{NH}_{2}$-terminal dystrophin and only faint traces of $\mathrm{COOH}$ terminal dystrophin in the heart. $A, B, C$, and $E, \times 180 ; D$ and $F \times 250$.

and at similar levels from adult cardiac muscle and from the heart biopsy of the XLDCM family member studied (Fig. 6). No amplification of the same transcript was detected in the skeletal muscle of various members of the XLDCM family, nor in normal skeletal muscle (Fig. 6).

\section{Discussion}

Dystrophin is a very large cytoskeletal protein expressed in all muscle types. While its localization is limited to the cytoplasmic surface of the sarcolemma in skeletal muscle, it is also expressed in the $T$ tubules in the cardiac myofibers $(27,28)$. Mutations in the dystrophin gene are responsible for both the severe Duchenne type muscular dystrophy (DMD) and its milder allelic variant Becker muscular dystrophy (BMD). In contrast to these two conditions, no clinical evidence of skeletal muscle involve- ment is present in families with a XLDCM secondary to a dystrophinopathy. Since in almost all these cases the muscle promoter is deleted $(8,9)$, transcription of the muscle isoform should have theoretically been abolished. However, no muscle weakness was detected, and dystrophin was visualized using immunocytochemistry in the muscle of these patients $(8,9)$.

We have recently characterized the pattern of dystrophin transcription in our XLDCM family and have found that the brain and the Purkinje-cerebellar cell isoforms were expressed at high levels in the skeletal muscle of the affected males (11). The overexpression of these two isoforms was therefore capable of preventing muscle degeneration. We have now also characterized the transcription of the recently described L-isoform (24) and shown that it does not play any significant role in normal muscle and heart, nor in this XLDCM family.

These studies, however, did not clarify the reason for the severe cardiac involvement in this XLDCM family. In particu- 

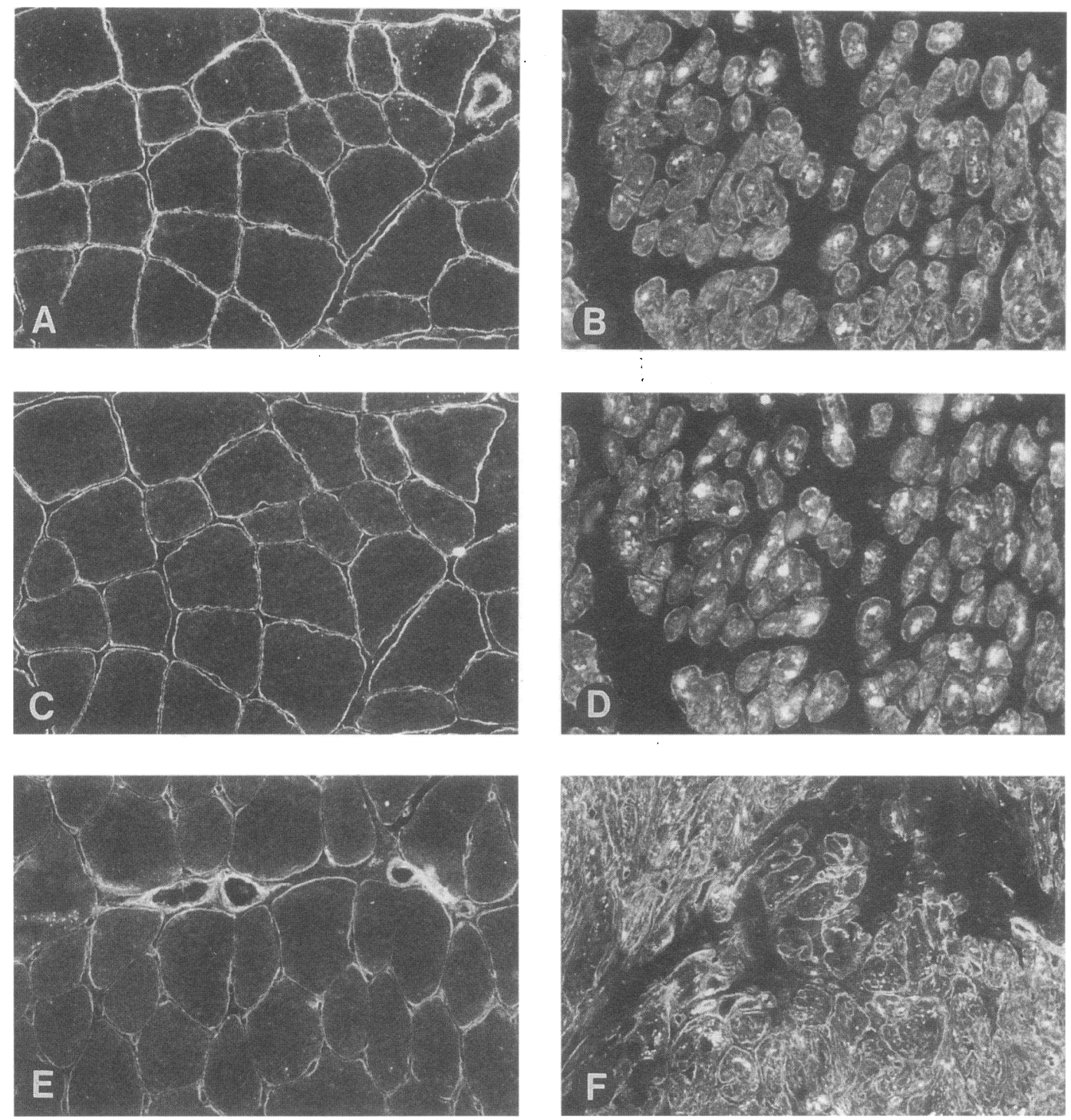

Figure 3. Cryostat sections of skeletal muscle $(A, C$, and $E)$ and cardiac muscle $(B, D$, and $F)$ from a XLDCM family affected individual, immunostained with antibodies to the $43-\mathrm{kD}(A$ and $B)$ and the $50-\mathrm{kD}(C$ and $D)$ DAGs, and to utrophin $(E$ and $F)$. Note the mild reduction in intensity of the DAGs in skeletal muscle, but the more severe reduction in the heart. Utrophin is also expressed in both tissues, but at higher levels in the cardiac muscle. $A, C, E$, and $F, \times 180 ; B$ and $D, \times 280$.

lar, the brain-type transcript has been shown to be physiologically expressed in the heart $(11,29)$ and its expression should therefore not have been affected by the deletion of the muscle promoter. In this report we demonstrate, however, that dystrophin was not detected immunocytochemically in the heart of the proband, using anti-dystrophin antibodies directed towards the $\mathrm{NH}_{2}$-terminal and mid-rod-domain region. In keeping with these results, no transcription for the same regions could be seen in the patient's heart.

Dystrophin is associated with a large oligomeric complex of sarcolemmal proteins, including $\alpha$-dystroglycan which provides a link to the extracellular matrix component, laminin (1416). Previous studies have indicated that all of these DAGs are reduced in skeletal muscle of the mdx mouse (30) and in DMD (31). In BMD the DAGs are only mildly to moderately reduced and there is a good correlation between the reduction of the DAGs and dystrophin and the severity of the phenotype $(32,33)$.
Immunocytochemical study of the 43- and 50-kD DAGs performed in this family showed mildly reduced levels in the skeletal muscle of the affected males. The DAGs immunoreactivity, however, was considerably reduced in the heart, indicating once again that the absence of dystrophin leads to a deficiency in DAGs. The absence of dystrophin and the deficiency of the DAGs is likely to render the cardiomyocytes susceptible to necrosis and this can account for the severe fibrosis we found in the heart. The levels of utrophin found in the heart were similar to those found in the DMD skeletal muscle (34). Despite its presence, however, utrophin did not provide a compensatory function and did not prevent the dystrophic process in the heart.

Immunocytochemistry performed in the heart using $\mathrm{COOH}$ terminal anti-dystrophin antibodies showed a weak but clear sarcolemmal staining in the cardiomyocytes. This signal most likely resulted from the expression of the dystrophin distal transcript Dp71 $(12,13,26)$ which is expressed physiologically in the heart (13). This hypothesis is suggested by the following 


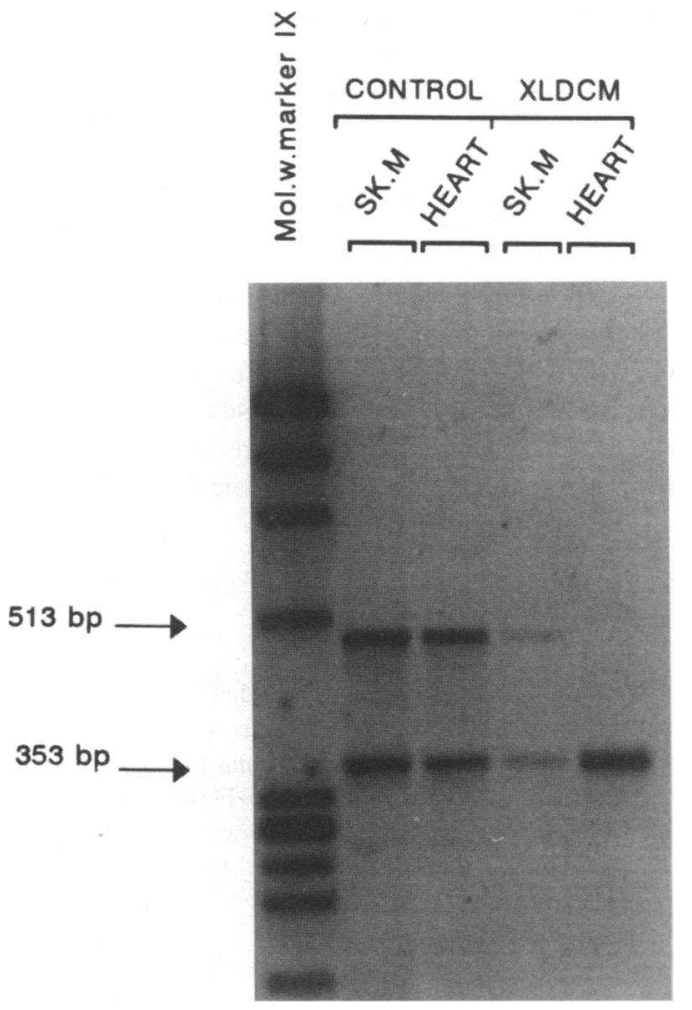

Figure 4. Co-amplification of merosin ( $\alpha 2$ laminin chain gene, $353 \mathrm{bp}$ ) and exon 30-33 of dystrophin (513 bp) from control muscle (Sk.M) and heart and from the same tissues from the XLDCM case.

observations: ( $a$ ) there was no immunoreactivity with antibodies directed towards other dystrophin domains; $(b)$ there was no transcription of the mid-rod-region of dystrophin; $(c)$ we successfully amplified the Dp71 unique mRNA isoform from the cardiac biopsy of the patient.

Dp71 is the major DMD gene product in brain and other nonmuscle tissues. It is undetected in adult skeletal muscle (12, 26) but expressed in the heart (13). The function of this DMD gene product is still unknown. The predicted amino acid sequence shows that Dp71 lacks the spectrin-like domain that confers a rod-shaped structure to dystrophin and it also lacks the $\mathrm{NH}_{2}$-terminal domain, which is assumed to bind actin. However, it contains the $\mathrm{COOH}$-terminal domain, which is the most conserved domain of dystrophin, and the cysteine-rich domain, which shares homology with the $\mathrm{Ca}^{2+}$-binding domain of $\alpha$ actinin. Since the association of dystrophin with the DAGs is mediated partly by the cysteine-rich domain and partly by the COOH-terminal domain (15), it is conceivable that Dp71 is also associated with the DAGs complex. In keeping with this hypothesis, Dp71 is associated with the plasma membrane in muscle $(12,35)$, and co-localizes with the dystrophin glycoprotein complex adjacent to the Z-disk (13). It has also been shown that overexpression of Dp71 in the skeletal muscle of transgenic $\mathrm{mdx}$ mouse is capable of restoring the DAGs levels $(36,37)$.

In our study we have detected a significant down-regulation of the DAGs in the cardiac muscle of our XLDCM family, despite the expression of normal levels of the Dp71 protein The DAG levels in the heart of this affected male were similar to those found in the muscle of individuals with severe BMD, where some dystrophin, but not the Dp71 is expressed. Our

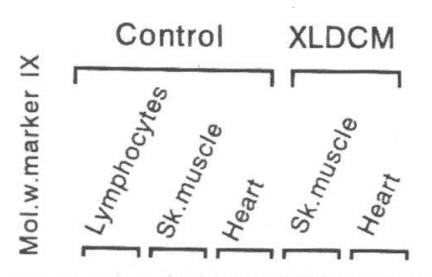

$A$
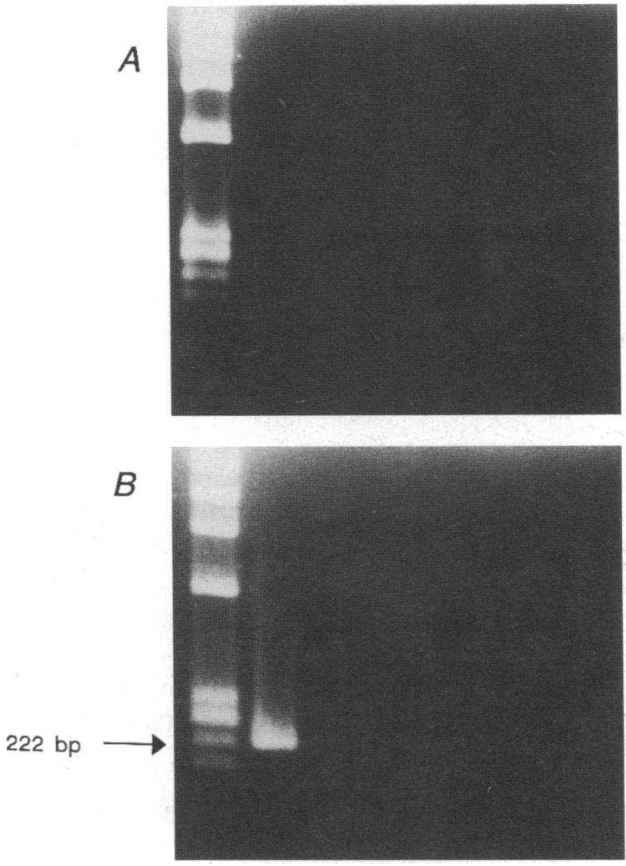

Figure 5. Amplification of the $\mathrm{L} 1$ isoform after one $(A)$ and after a second round of PCR $(B)$ in various tissues from controls and from the XLDCM propositus. The expected size 222-bp fragment was amplified only from the lymphocytes after two PCR cycles.

result therefore indirectly suggests that the physiological levels of Dp71 partially contribute to the DAG binding in the heart. This is however not sufficient to avoid the onset and progression of the cardiac pathology. This might indicate that the role of Dp71 in the heart is different from that of dystrophin; the fact Dp71 lacks both the spectrin-like repeats and the actin-binding domain of dystrophin further reinforces this view. In view of the partial contribution of Dp71 to the DAG binding, it would be interesting to verify if the rare DMD patients with a mutation affecting the production of both the major dystrophin isoforms and Dp71 suffer from a more severe cardiomyopathy then patients with mutations affecting the major dystrophin isoforms in isolation.

The complete absence of the major dystrophin isoforms in the heart in individuals that express them in the skeletal muscle has not been reported before. The pattern of dystrophin expression in the heart of these individuals is similar to that found in DMD, while in the skeletal muscle it is comparable with that of a very mild BMD. The most likely explanation for the mechanism of disease in this family is the removal of cis-acting sequences essential for transcription of dystrophin in the heart. It is of interest that these putative sequences had no role on the Dp71 transcription in the skeletal muscle and heart of our patient. In particular, the Dp71 mRNA levels in the heart of the patient were similar to those obtained in the control hearts; moreover, no upregulation of the Dp71 isoform was detected 


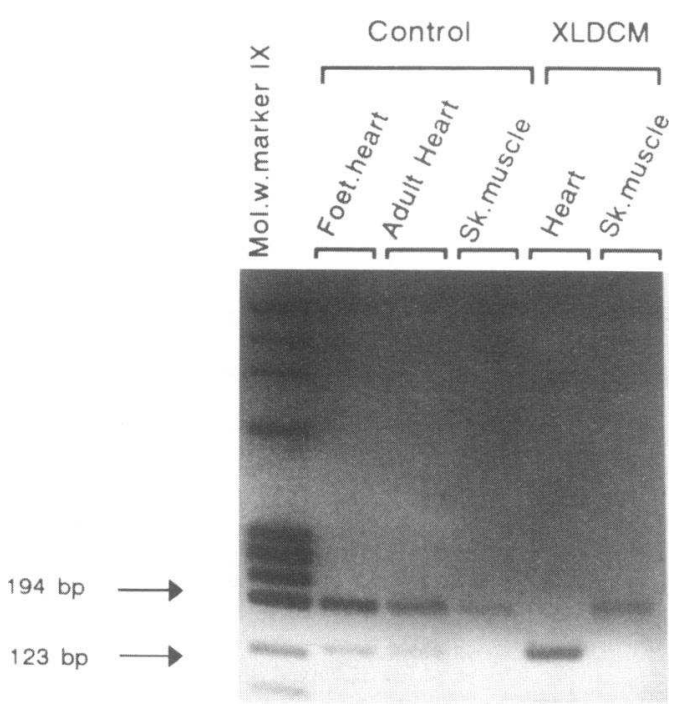

Figure 6. Co-amplification of Dp71 (123 bp) and exon 30-31 of dystrophin (194 bp) from normal foetal and adult heart, from adult skeletal muscle (Sk. muscle) and from heart and skeletal muscle of the XLDCM proband.

in the skeletal muscle of this individual, contrary to what found for both the brain and Purkinje-cells isoforms. These results indicate the absence of transcriptional interference between the 5 ' promoters and the Dp71 promoter. The same deduction can also be applied to the L-type isoform.

As previously suggested (11), these putative regulatory sequences may lie within the very large first dystrophin intron (38). Analysis of the sequence of this intron has shown regions of homology to various muscle specific regulatory elements, such as an "E box" (39), a MEF1 binding site (40), and a MEF2 binding site (41), all involved in binding or enhancing the function of various members of the helix-loop-helix protein family $(42,43)$.

Although members of the helix-loop-helix family, such as MyoD1 or MEF2, are not detected in heart, an "E box" has been found in the regulatory region of the human cardiac actin promoter and has been shown to be important for its expression in myocardiocytes (44). Similarly, a MEF2 site has been identified in the regulatory region of several genes mainly expressed in the heart, such as the cardiac troponin $T(45,46)$ and rat cardiac myosin light chain-2 gene (47).

Several genes expressed both in the cardiac and skeletal muscle have recently been shown to have distinct transcriptional pathways involved in the cardiac and skeletal muscle-specific gene expression. In this respect the slow/cardiac troponin C (cTnC) gene is expressed in adult cardiac and slow skeletal muscle (48) and only transiently in embryonic fast skeletal myotubes (49). While the cTnC gene expression in embryonic skeletal muscle is regulated by a skeletal muscle-specific, developmentally regulated transcriptional enhancer located within the first intron of the gene, a distinct and independent transcriptional enhancer, located within the immediate $5^{\prime}$ flanking region of the cTnC gene regulates its expression in the heart (50).

It is therefore conceivable that a separate transcriptional pathway is responsible for dystrophin expression in the skeletal muscle and heart. The sequences we have already suggested might be responsible for driving dystrophin transcription in the heart, as well as others located in the large intron 1.
Further studies aimed at characterizing in detail these putative sequences are still needed. This information will also be of value when designing gene therapy strategies for DMD.

In conclusion, our data suggest that the deletion found in our family with XLDCM selectively affects dystrophin expression in the heart but not in the skeletal muscle. The Dp71 dystrophin isoform, although expressed in the cardiac tissue, is not capable of maintaining adequate DAG levels and therefore of restoring dystrophin function. From our data it is also possible to hypothesize that other genes that are co-expressed in skeletal muscle and heart might also undergo selective transcriptional impairment in this latter tissue and therefore are potential candidates for autosomically inherited dilated cardiomyopathies.

\section{Acknowledgments}

The authors wish to thank Yan Wang and Anna Mateddu for technical assistance and Karen Davidson for the photographs.

This work was financed by a grant of the Muscular Dystrophy Group (MDG) of Great Britain and Northern Ireland to Francesco Muntoni and by a Telethon grant to Carlo Cianchetti. Y. Wang is supported by MDG.

\section{References}

1. Codd, M. B., D. D. Sugrue, B. J. Gersh, and L. J. Melton. 1989. III. Epidemiology of idiopathic dilated and hypertrophic cardiomyopathy: a population-based study in Olmsted County, Minnesota. 1975-1984. Circulation. 80:564-572.

2. Michels, V. V., P. P. Moll, F. A. Miller, A. J. Tajik, J. S. Cru, D. J. Driscoll J. C. Burnett, J. C. Richard, R. J. Rodeheffer, J. H. Chesebro, and H. D. Tazelaar. 1992. The frequency of familial dilated cardiomyopathy in a series of patients with idiopathic dilated cardiomyopathy. N. Engl. J. Med. 326:77-82.

3. Graber, H. L., D. V. Unvererth, P. B. Baker, J. M. Ryan, N. Baba, and C. F. Wooley. 1986. Evolution of a hereditary conduction and muscle disorder: a study involving a family with six generations affected. Circulation. 74:21-35.

4. de Papepa, A., Y. Kluyskens, J. P. van Durme, K. Naudts, R. Claeys, and X. de Wagter. 1991. Familial idiopathic dilated cardiomyopathy. Acta Cardiol. 46:577-582.

5. Valantine, H. A., S. H. Hunt, M. B. Fowler, M. E. Billingham, and J. S. Schroeder. 1989. Frequency of familial nature of dilated cardiomyopathy and usefulness of cardiac transplantation in this subset. Am. J. Cardiol. 63:959-963.

6. Berko B. A., and M. Swift. 1987. X-linked dilated cardiomyopathy. $N$. Engl. J. Med. 316:1186-1191.

7. Towbin, J. A., J. F. Hejtmancik, P. Brink, B. Gelb, X. M. Zhu, J. S. Chamberlain, E. R. McCabe, and M. Swift. 1993. X-linked cardiomyopathy. Molecular genetic evidence of linkage to the Duchenne muscular dystrophy (dystrophin) gene at the Xp21 locus. Circulation. 87:1854-1865.

8. Muntoni, F., M. Cau, R. Congiu, A. Ganau, G. Arvedi, A. Mateddu, M. G. Marrosu, C. Cianchetti, A. Realdi, A. Cao, and M. A. Melis. 1993 Deletion of the dystrophin muscle-promoter region associated with X-linked dilated cardiomyopathy. N. Engl. J. Med. 329:921-925.

9. Yoshida, K., S. Ikeda, A. Nakamura, M. Kagoshima, S. Takeda, S. Shoji, and N. Yanagisawa. 1993. Molecular analysis of the Duchenne muscular dystrophy gene in patients with Becker muscular dystrophy presenting with dilated cardiomyopathy. Muscle \& Nerve 16:1161-1166.

10. Kass, S., C. MacRae, H. L. Graber, E. A. Sparks, D. McNamara, H Boudoulas, C. T. Basson, P. B. Baker, R. J. Cody, M. C. Fishman, N. Cox, A Kong, C. F. Wooley, J. G. Seidman, and C. E. Seidman. 1994. A gene defect that causes conduction system disease and dilated cardiomyopathy maps to chromosome 1p1-1q1. Nat. Genet. 7:546-551.

11. Muntoni, F., M. A. Melis, A. Ganau, and V. Dubowitz. 1995. Transcription of the dystrophin gene in normal tissues and in skeletal muscle of a family with X-linked dilated cardiomyopathy. Am. J. Hum. Genet. 56:151-157.

12. Lederfein, D., Z. Levy, N. Augier, D. Mornet, G. Morris, O. Fuchs, D. Yaffe, and U. Nudel. 1992. A 71-kilodalton protein is a major product of the Duchenne muscular dystrophy gene in brain and other nonmuscle tissues. Proc. Natl. Acad. Sci. USA. 89:5346-5350.

13. Fabbrizio E., U. Nudel, G. Hugon, A. Robert, F. Pons, and D. Mornet. 1994. Characterisation and localisation of a $77 \mathrm{kDa}$ protein related to the dystrophin gene family. Biochem. J. 299:359-365. 
14. Campbell, K.P., and S.D. Kahl. 1989. Association of dystrophin and an integral membrane glycoprotein. Nature (Lond.). 338:259-262.

15. Ervasti, J. M. S., S. D. Kahl, and K. P. Campbell. 1991. Membrane organization of the dystrophin-glycoprotein complex. Cell. 66:1121-1131.

16. Ibraghimov-Beskrovnaya, O., J. M. Ervasti, C. J. Leveille, C. A. Slaughter, S. W. Sernett, and K. P. Campbell. 1992. Primary structure of dystrophin-associated glycoproteins linking dystrophin to the extracellular matrix. Nature (Lond.). 355:696-702.

17. Dubowitz, V. 1985. Muscle Biopsy: a practical approach. Second edition. Bailliere Tindall, Eastbourne.

18. Muntoni, F., A. Mateddu, C. Cianchetti, M. G. Marrosu, M. Cau, R. Congiu, A. Cao, and M. A. Melis. 1993. Dystrophin analysis using a panel of anti-dystrophin antibodies in Duchenne and Becker muscular dystrophy. J. Neurol. Neurosurg. Psych. 56:26-31.

19. Sewry, C. A., A. Sansome, K. Matsumura, K. P. Campbell, and V. Dubowitz. 1994. Deficiency of the 50kDa dystrophin-associated glycoprotein and abnormal expression of utrophin in two south Asian cousins with variable expression severe childhood autosomal recessive muscular dystrophy. Neurom. Disord. 4:121-129.

20. Sewry, C. A., J. Philpot, D. Mahony, L. Wilson, F. Muntoni, and V. Dubowitz. 1995. Expression of laminin subunits in congenital muscular dystrophy. Neurom. Disord. In press.

21. Chomczynsky, P., and N. Sacchi. 1987. Single step method of RNA isolation by acid guanidinium thiocyanate phenol chloroform extraction. Anal. Biochem. 162:156-159.

22. Muntoni, F., and P. N. Strong. 1989. Transcription of the dystrophin gene in Duchenne muscular dystrophy muscle. FEBS (Fed. Eur. Biochem. Soc.) Lett. 252:95-98.

23. Koenig. M., A. P. Monaco, and L. M. Kunkel. 1988. The complete sequence of dystrophin predicts a rod-shaped cytoskeletal protein. Cell. 53:219-28.

24. Nishio, H., Y. Takeshima, N. Narita, H. Yanagawa, Y. Suzuki, Y. Ishikawa, Y. Ishikawa, R. Minami, H. Nakamura, and M. Matsuo. 1994. Identification of a novel first exon in the human dystrophin gene and of a new promoter located more than $500 \mathrm{~kb}$ upstream of the nearest known promoter. J. Clin. Invest. 94:1037-1042.

25. Vuolteenaho, R., M. Nissinen, K. Sainio, M. Byers, R. Eddy, H. Hirvonen, T. B. Shows, H. Sariola, E. Envall, and K. Tryggvason. 1994. Human laminin $M$ chain (merosin): complete primary structure, chromosomal assignment, and expression of M and A chains in human fetal tissues. J. Cell Biol. 124:381-394.

26. Hugnot, J. P., H. Gilgenkrantz, N. Vincent, P. Chafey, G. E. Morris, A. P. Monaco, Y. Berwald-Netter, A. Koulakoff, J. C. Kaplan, A. Khan, and J. Chelly 1992. Distal transcript of the dystrophin gene initiated from an alternative first exon and encoding a 75-kDa protein widely distributed in nonmuscle tissues. Proc. Natl. Acad. Sci. USA. 89:7506-7510.

27. Bies, R. D., D. Friedman, R. Roberts, M. B. Perryman, and C. T. Caskey. 1992. Expression and localization of dystrophin in human cardiac purkinje fibers Circulation. 86:147-153.

28. Klietsch, R., J. M. Ervasti, W. Arnold, K. P. Campbell, and A. O. Jorgensen. 1993. Dystrophin-glycoprotein complex and laminin colocalize to the sarcolemma and transverse tubules of cardiac muscle. Circ. Res. 72:349-360.

29. Bies, R. D., S. F. Phelps, M. D. Cortez, R. Roberts, C. T. Caskey, and J. S. Chamberlain. 1992. Human and murine dystrophin mRNA transcripts are differentially expressed during skeletal muscle, heart and brain development. Nucleic Acids Res. 20:1725-1731.

30. Ohlendieck, K., and K. P. Campbell. 1991. Dystrophin associated-protein are greatly reduced in skeletal muscle form mdx mice. J. Cell Biol. 115:1685 1694.

31 Ohlendieck, K., K. Matsumura, V. V. Ionasescu, J. A. Towbin, E. P. Bosch, S. L. Weinstein, S. W. Sernett, and K. P. Campbell. 1993. Duchenne muscular dystrophy: deficiency of dystrophin-associated proteins in the sarcolemma. Neurology. 43:795-800.

32 Matsumura, K., I. Nonaka, F. M. Tome', K. Arahata, H. Collin, F. Leturcq,
D. Recan, J. C. Kaplan, M. Fardeau, and K. P. Campbell. 1993. Mild deficiency of dystrophin-associated proteins in Becker muscular dystrophy patients havin in-frame deletions in the rod domain of dystrophin. Am. J. Hum. Genet. 53:409416.

33 Matsumura K., A. H. M. Burghes, M. Mora, F. M. S. Tome', L. Morandi, F. Cornelio, F. Leturcq, M. Jeanpierre, J. C. Kaplan, P. Reinert, M. Fardeau and J. R. Mendell. 1994. Immunohistochemical analysis of dystrophin-associated proteins in Becker/Duchenne muscular dystrophy with huge in-frame deletions in the $\mathrm{NH}_{2}$-terminal and rod domains of dystrophin. J. Clin. Invest. 93:99-105.

34. Voit, T., K. Haas, J. Léger, F. Pons, and J. J. Léger. 1991. Xp21 dystrophin and $6 \mathrm{q} 24$ dystrophin related protein: comparative immunolocalisation using multiple antibodies. Am. J. Pathol. 139:69-976.

35. Rapaport D., D. S. Greenberg, M. Tal, D. Yaffe, and U. Nudel. 1993. Dp71, the nonmuscle product of the Duchenne muscular dystrophy gene is associated with the cell membrane. FEBS (Fed. Eur. Biol. Soc.) Lett. 328:197-202.

36. Cox, G. A., Y. Sunada, K. P. Campbell, and J. S. Chamberlain. 1994. Dp71 can restore the dystrophin-associated glycoprotein complex in muscle but fails to prevent dystrophy. Nature Genet. 8:333-339.

37. Greenberg, D. S., Y. Sunada, K. P. Campbell, D. Yaffe, and U. Nudel. 1994. Exogenous Dp71 restores the levels of dystrophin associated proteins but does not alleviate muscle damage in mdx mice. Nature Genet. 8:340-344.

38. Klamut, H. J., S. B. Gangopadhyay, R. Worton, and P. N. Ray. 1990. Molecular and functional analysis of the muscle specific promoter region of the Duchenne muscular dystrophy gene. Mol. Cell. Biol. 10:193-203.

39. Weintrab, H., R. Davis, S. Tapscott, M. Thayer, M. Krause, R. Benezta, T. K. Blackwell, D. Turner, R. Rupp, S. Hollenberg, Y. Zhuang, and A. Lassar. 1991. The myoD gene family: Nodal point during specification of the muscle cell lineage. Science (Wash. DC). 251:761-766.

40. Buskin, J. N., and S. D. Hauschka. 1989. Identification of a myocyte nuclear factor that binds to the muscle-specific enhancer of the mouse muscle creatine kinase gene. Mol. Cell. Biol. 9:2627-2640.

41. Gosset, L. A., D. J. Kelvin, E. A. Sternberg, and E. N. Olson. 1989. A new myocyte-specific enhancer-binding factor that recognizes a conserved element associated with multiple muscle-specific genes. Mol. Cell. Biol. 9:5022-5033.

42. Wright, W. E., D. A. Sassoon, and V. K Lin. 1989 Myogenin, a factor regulating myogenesis, has a domain homologous to MyoD. Cell. 56:607-617.

43. Edmonson, D. G., T. C. Cheng, P. Cserjesi, T. Chakraborty, and E. N. Olson. 1992. Analysis of the myogenin promoter reveals an indirect pathway for positive autoregulation mediated by the muscle specific enhancer factor MEF-2. Mol. Cell. Biol. 12:3665-3667.

44. Sartorelli, V., N. A. Hong, N. H. Bishopric, and L. Kedes. 1992. Myocardial activation of the human alpha-actin promoter by helix-loop-helix proteins. Proc. Natl. Acad. Sci. USA. 89:4047-4051.

45. Iannello, R. C., J. H. Mar, and C. P. Ordhal. 1991. Characterization of a promoter element required for transcription in myocardial cells. J. Biol. Chem 266:3309-3316

46. Cserjesi, P., and E. N. Olson. 1991. Myogenin induces the myocytespecific enhancer binding factor MEF-2 independently of other muscle-specific gene products. Mol. Cell. Biol. 11:4854-4862.

47. Navankasattusas, S., H. Zhu, A. V. Garcia, S. M. Evans, and K. R. Chien 1992. A ubiquitous factor (HF-1a) and a distinct muscle factor (HF-1b/MEF-2) from an E-box-independent pathway for cardiac muscle gene expression. Mol. Cell. Biol. 12:1469-1479.

48. Parmacek, M. S., and J. M. Leiden. 1989. Structure and expression of the murine slow/ cardiac troponin C gene. J. Biol. Chem. 264:13217-13225.

49. Dhoot, G. K., and S. V. Perry. 1979. Distribution of polymorphic forms of troponin components and tropomyosin in skeletal muscle. Nature (Lond.). 278:714-718.

50. Parmacek, M. S., A. J. Vora, T. Shen, E. Barr, F. Jung, and J. M. Leiden. 1992. Identification and characterization of a cardiac-specific transcriptional regulatory element in the slow/cardiac troponin C gene. Mol. Cell. Biol. 12:19671976 